\title{
A Simplified Approach for Fabrication of One-Piece Hollow Interim Obturator for the Prosthodontic Treatment of Hemimaxillectomy Patient-A Clinical Report
}

\author{
Jaswinder Kaur ${ }^{1}$ \\ ${ }^{1}$ Department of Prosthodontics, Baba Jaswant Singh Dental College, \\ Hospital and Research Institute, Ludhiana, Punjab, India
}

\begin{abstract}
Address for correspondence Jaswinder Kaur, MDS, Department of Prosthodontics, Baba Jaswant Singh Dental College, Hospital and Research Institute, Ludhiana, Punjab, India (e-mail: dr.jaswinder.kaur@gmail.com).
\end{abstract}

Dent J Adv Stud 2019;7:135-138

\begin{abstract}
Most common problems faced by a patient with resected maxilla are reduced retention, support, and stability. A successful prosthesis should meet the physiological, psy-

Keywords

- hemimaxillectomy

- hollow chological, and aesthetic needs of the patient. This article describes the procedure for the rehabilitation of hemimaxillectomy patient with one-piece hollow obturator using simple technique, reducing laboratory time.

- obturator
\end{abstract}

\section{Introduction}

The most common treatment option for patient with maxillary malignant tumor is the surgical excision of the tumor leaving an oronasal/antral defect that further results in impaired speech and mastication. ${ }^{1}$ Obturator is a maxillofacial prosthesis used to close, cover, or maintain the integrity of the oral and nasal compartments resulting from a congenital, acquired, or developmental disease process, such as cancer, cleft palate, osteonecrosis of the palate, the prosthesis facilitates speech, and deglutination by replacing those tissues lost because of the disease process and can, as a result, reduce nasal regurgitation and hypernasal speech, and improve articulation, deglutination, and mastication. ${ }^{2}$ Obturators can be surgical, interim, and definitive depending upon the time of fabrication.

This clinical report presents rehabilitation of hemimaxillectomy patient with one-piece hollow bulb obturator by a simplified approach.

\section{Case Report}

A male patient aged 45 years presented with complaint of dislodging prosthesis leading to difficulty in drinking, chewing, and speech and unaesthetic appearance due to absence of teeth. His complete history revealed that he got operated for squamous cell carcinoma with hemimaxillectomy 4 months back. On clinical examination, Armani's class I defect was found on the left side extending from the center to the soft palate (-Fig. 1). Patient was wearing surgical obturator prosthesis that was under extended. An interim obturator with teeth and hollow bulb was planned as healing was not satisfactory in the defect area.

Maxillary and mandibular primary impressions ( - Fig. 2) were made using irreversible hydrocolloid impression material (Jeltrate Chromatic Alginate, Dentsply India). Impressions were poured in dental plaster (Kalabhai Karson). Maxillary special tray was constructed using shellac base plate and green stick compound was used for tracing borders for recording functional limit of adjacent soft tissues. Handle of the special tray was cut down, tray was loaded with alginate, seated in patients mouth, and over-impression was taken. Final impression ( - Fig. 3) was examined for necessary anatomical details and poured in type III gypsum product and master cast was obtained.

Conventional procedures, that is, jaw relations, trial, wax-up, flasking, and dewaxing were followed. At the stage of packing, a layer of modelling wax (Dental Products of India [DPI]) was adapted in the defect area on the invested plaster in the counter part of the flask. From the modelling wax, four widely spaced windows were made to act as reference stops. Over this, a very thin layer of autopolymerizing acrylic resin was adapted,
DOI https://doi.org/

$10.1055 / \mathrm{s}-0039-3402664$

ISSN 2321-1482.
(C2019 Bhojia Dental College and Hospital affiliated to Himachal

Pradesh University
License terms

()(1) $\Theta \circledast$ 


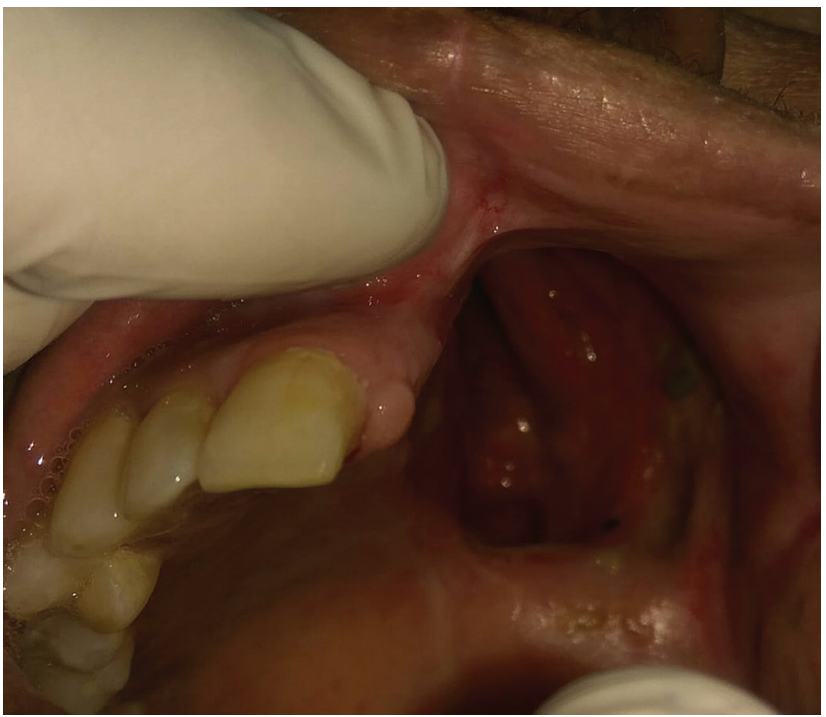

Fig. 1 Intraoral Armani Class I maxillary defect.

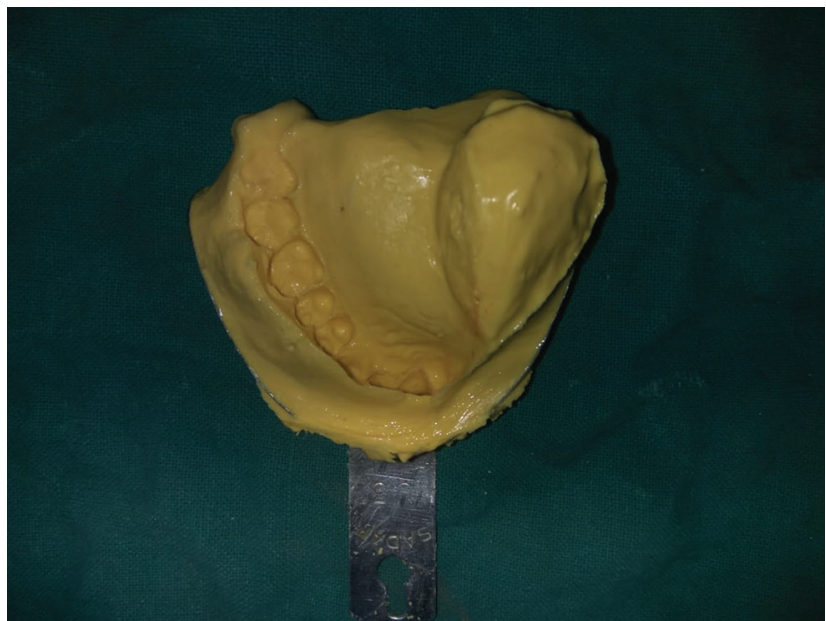

Fig. 2 Primary impression.

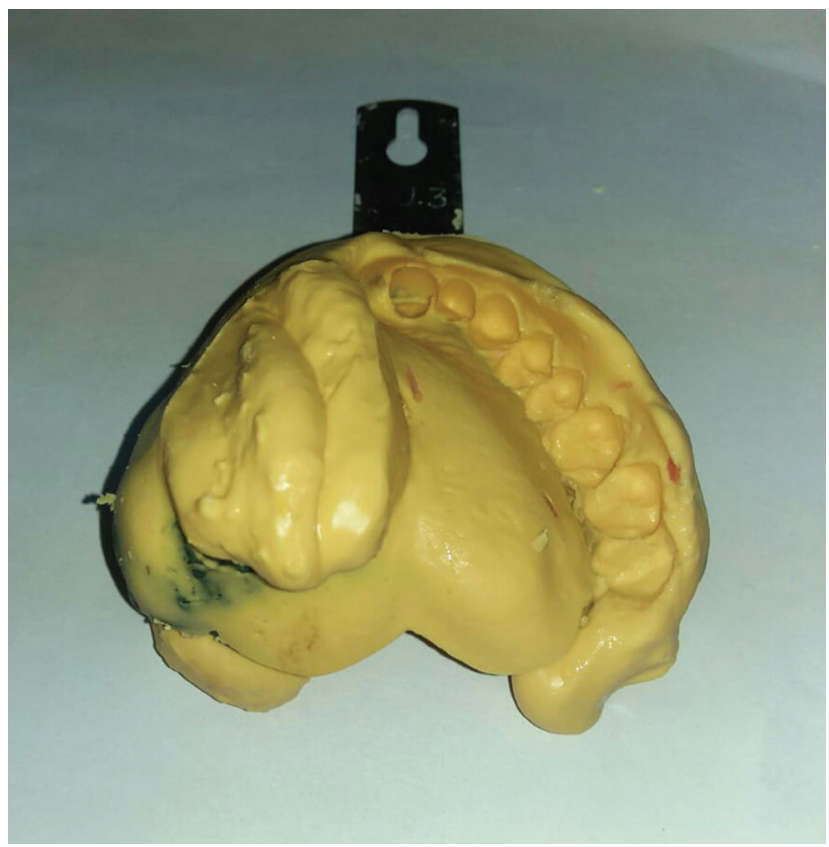

Fig. 3 Final impression. allowed to cure, and then retrieved from the defect area. Selfcure resin was molded in the form of a thin lid and pressed over the acrylic shim to obtain hollow bulb. Shim was finished to keep minimally thick and kept aside (-Fig. 4). After wax elimination, separating media was applied in the defect area. Heat polymerizing acrylic resin (DPI) was mixed and a layer was placed in the defect area. The acrylic shim was placed ensuring complete seating with reference to the stops. Heat cure material was packed into the mold and processed in a conventional manner. The interim obturator was retrieved as one piece, finished and polished (-Fig. 5). The prosthesis was checked for fit and retention in patient's mouth (-Figs. 6 and 7). Patient was given instructions for insertion, removal, and cleaning of the prosthesis and he was recalled for follow-up at periodic intervals.

\section{Discussion}

The objectives of prosthodontic rehabilitation for patients with palatal defects are separation of oral cavities from nasal cavities allowing sufficient deglutination and articulation, prevention of enophthalmos by providing support to the orbital contents, and restoration of contour of midfacial region by providing support to the adjacent soft tissues and esthetically acceptable result. ${ }^{3}$

Prosthodontic rehabilitation is simple and pleasing and offers acceptable prognosis in patients having acquired maxillary defects as compared with mandibular defects. ${ }^{4}$ Patient presented in this report falls into Armani class I classification that is most frequently found in maxillectomy patients. ${ }^{5}$

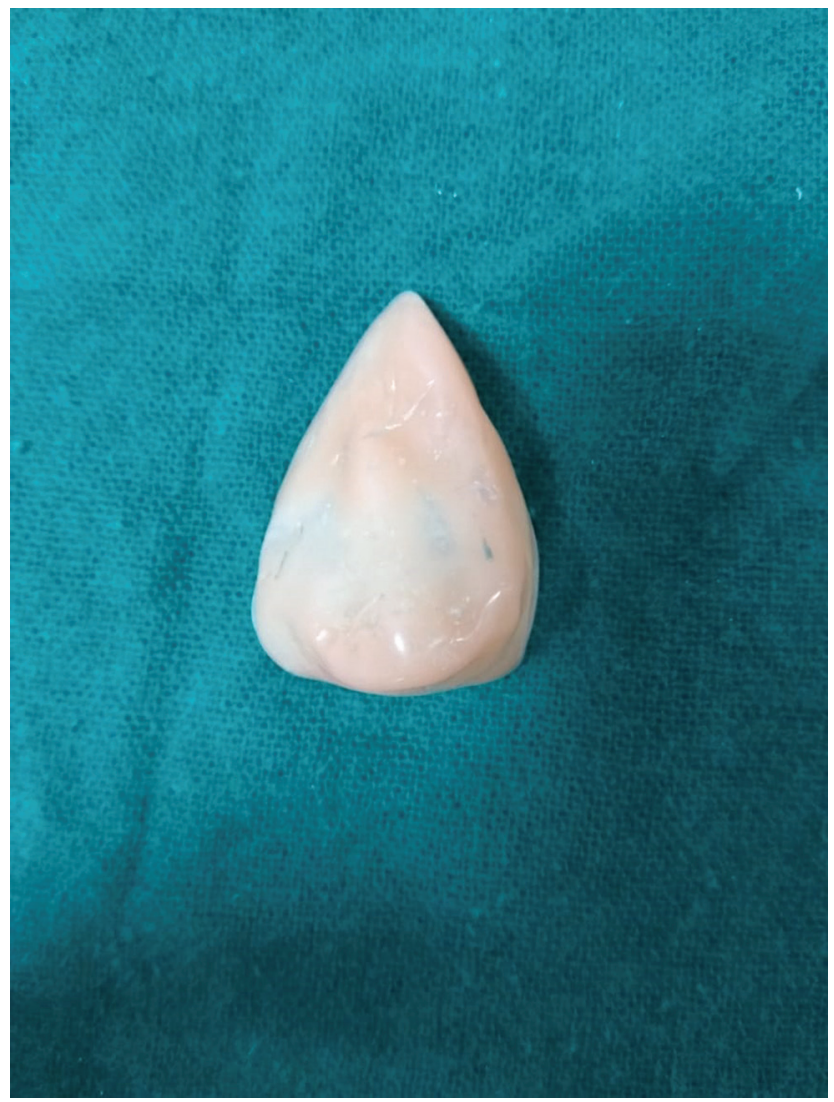

Fig. 4 Hollow shim. 


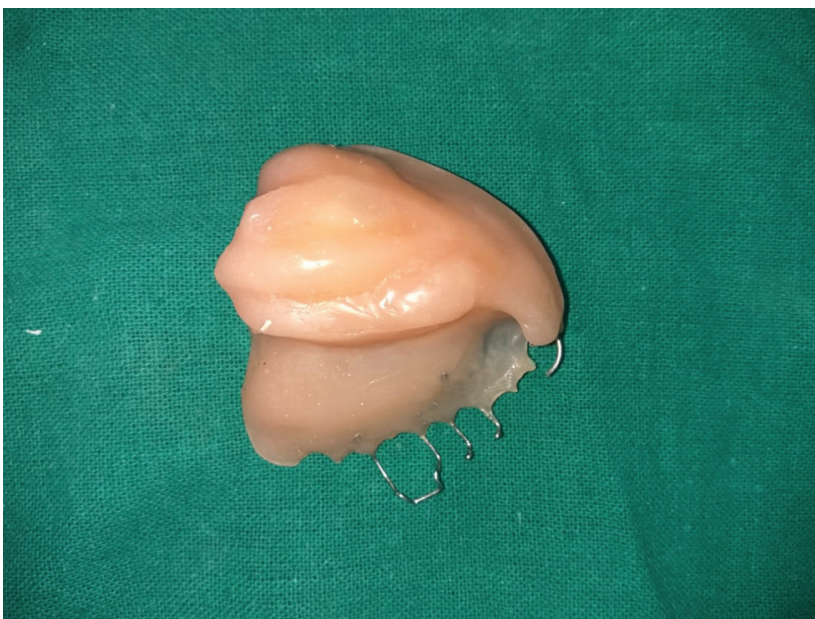

Fig. 5 Final prosthesis.

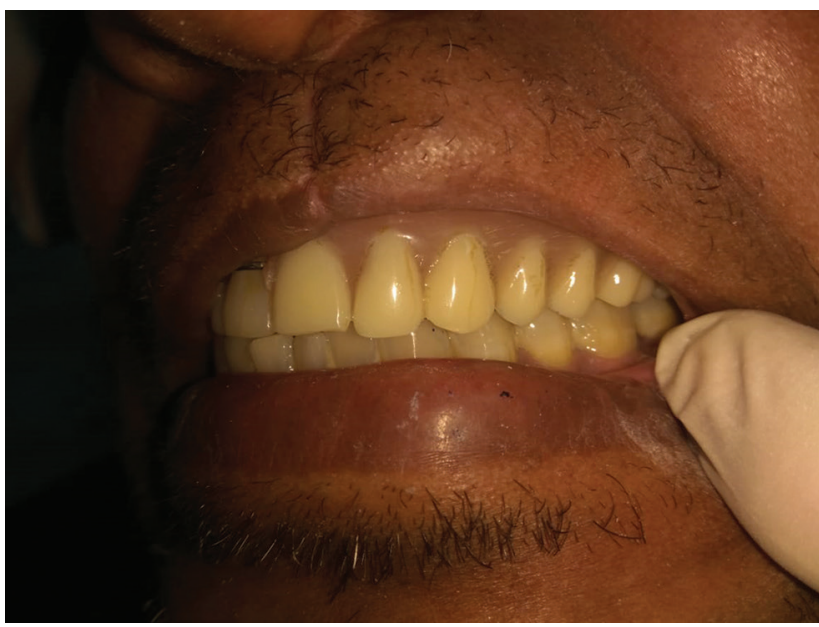

Fig. 6 Final prosthesis intraoral view.

Surgery of these defects results in hypernasality and deterioration of speech along with escape of fluids into nasal cavity. ${ }^{6}$

A definitive obturator is indicated only after there is complete healing at the surgical site and the patient is physically and emotionally ready for the necessary restorative care. ${ }^{7}$ For some patients particularly with large defects, appropriate function and comfort cannot be sustained without construction of a new prosthesis or a significant modification of the immediate and delayed obturator. Addition of denture teeth provides psychological benefit to the patient in case teeth are extracted during resection. A well-made interim obturator can serve as a backup prosthesis, which may be useful when definitive prosthesis needs to be repaired, relined, or rebased. ${ }^{8}$

Wu and Schaaf ${ }^{9}$ reported that hollow obturator resulted in significant increased reduction in weight (i.e., 6.55-33.06\%) depending on defect size and advocated hollow bulb obturator for hemimaxillectomy patient.

Various authors have used different techniques for the fabrication of hollow obturator. Matalon and LaFuente ${ }^{10}$ used sugar to fill the defect during processing, which was later removed by drilling holes and sealing it with

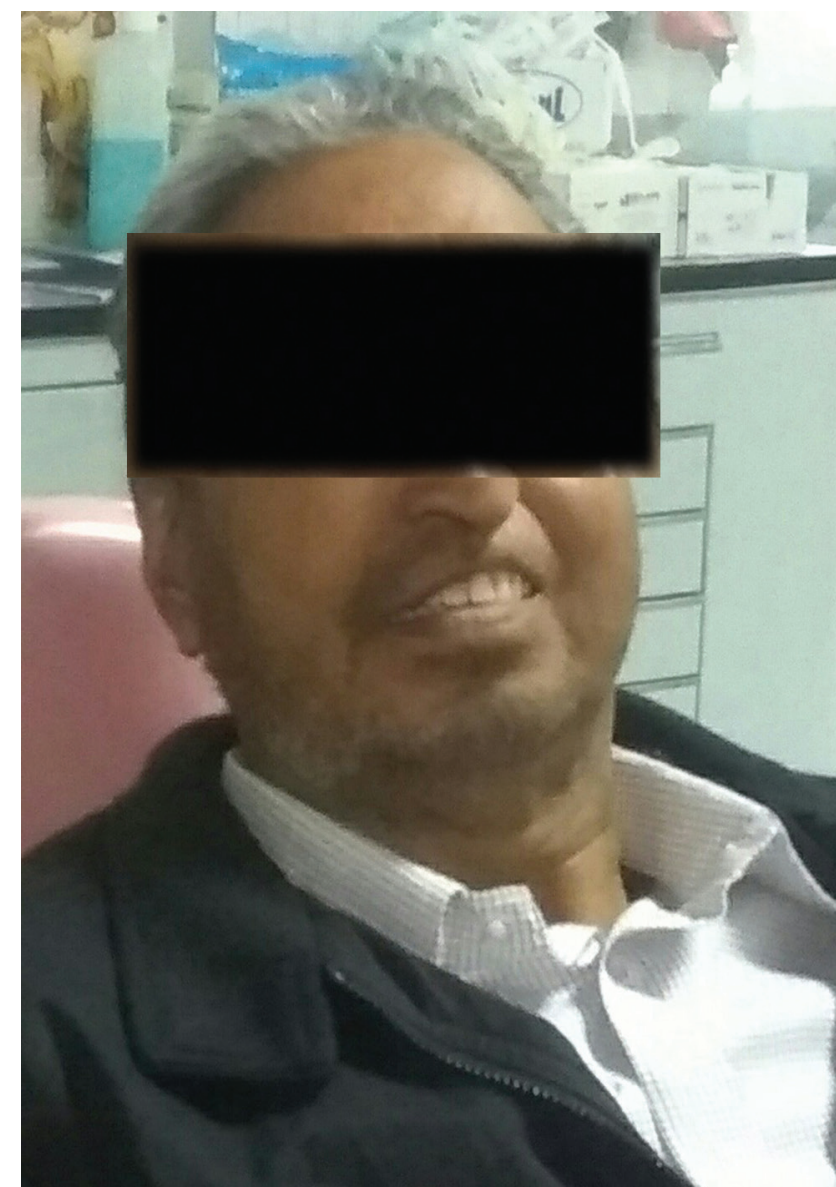

Fig. 7 Post-treatment view of the patient.

autopolymerizing resin before finishing and polishing. Crushed ice, modeling clay, alum salt, wax bolus, balloon, etc. have also been used by various authors, as an alternative to sugar to fill the defect. ${ }^{11,12}$

Hollow bulb obturator, being light, is more comfortable and efficient and provides physiological and psychological benefits, exerts less pressure to the adjacent tissues encouraging regeneration, and prevents excessive atrophy and functional changes in muscle balance. ${ }^{7}$ Hollowing the obturator portion results in achieving better cantilever mechanics of suspension and prevents overstressing of supportive tissues. ${ }^{13}$

The obturator in this case was made hollow by a simple technique without the need of duplicating cast and ensuring that self-cure acrylic resin does not come in direct contact with the tissues. Both polished and tissue surface of the denture were in heat cure acrylic resin. There was no need to fill defect with sugar or salt or any other material that later on necessitates removal of the same by drilling holes and altering polished surface of the denture. Fabrication of one-piece heat cure hollow obturator with unaltered polished surface, using simplified approach, is the characteristic feature of this case.

Open obturator lightens the weight of the prosthesis, and it is easy to fabricate and facilitate hygiene but acts as reservoir for food and nasal secretions; so, frequent cleaning of the 
prosthesis is required. A closed obturator does not allow collection of fluids and decrease air space present in the defect of maxilla; however, fluids still can be absorbed through the pores in the acrylic resin seal that is present between the lid portion and obturator, leading to infection by creating nonhygienic conditions. In the present case, one-piece obturator was fabricated, so there was no issue of imperfect sealing. Hollow obturator has been fabricated in the past that had removable lid, thus combining benefits of both open and closed systems. ${ }^{14}$

Application of prosthodontics principles and efficacious design should be implemented so that there is not just survival from the disease that is considered but the patient should be able to lead a normal functioning life.

\section{Conclusion}

The rehabilitation of a patient with acquired maxillary defect following hemimaxillectomy is a prosthodontic challenge. This clinical report describes the successful rehabilitation of such patient with one-piece hollow interim obturator.

\section{Conflict of Interest}

None declared.

\section{References}

1 Lethaus B, Lie N, de Beer F, Kessler P, de Baat C, Verdonck HW. Surgical and prosthetic reconsiderations in patients with maxillectomy. J Oral Rehabil 2010;37(2):138-142
2 The glossary of prosthodontic terms. J Prosthet Dent 2017;117(5S):e1-e105

3 Wang RR. Sectional prosthesis for total maxillectomy patients: a clinical report. J Prosthet Dent 1997;78(3):241-244

4 Alhajj MN, Ismail IA, Khalifa N. Maxillary obturator prosthesis for a hemimaxillectomy patient: a clinical case report. The Saudi Journal for Dental Research 2016;7:153-159

5 Aramany MA. Basic principles of obturator design for partially edentulous patients. Part I: classification. J Prosthet Dent 1978;40(5):554-557

6 Chalian VA, Drane JB, Standish SM. Maxillofacial prosthetics. Multidisciplinary Practice. Baltimore: The Williams and Wilkins Co.; 1971:133-148

7 Keyf F. Obturator prostheses for hemimaxillectomy patients. J Oral Rehabil 2001;28(9):821-829

8 Beumer J, Curtis TA, Marunick M (eds). Maxillofacial Rehabilitation: Prosthodontic and Surgical Considerations. St. Louis, MO: Ishiyaku EuroAmerica;1979:247

$9 \mathrm{Wu}$ YL, Schaaf NG. Comparison of weight reduction in different designs of solid and hollow obturator prostheses. J Prosthet Dent 1989;62(2):214-217

10 Matalon $\mathrm{V}$, LaFuente $\mathrm{H}$. A simplified method for making a hollow obturator. J Prosthet Dent 1976;36(5):580-582

11 Patil PG, Nimbalkar-Patil S. Lost wax-bolus technique to process closed hollow obturator with uniform wall thickness using single flasking procedure. J Indian Prosthodont Soc 2017; 17(1):84-88

12 Hollow bulb one piece maxillary definitive obturator- a clinical case report. Contemp Clin Dent 2017;8:167-170

13 Brown KE. Clinical considerations improving obturator treatment. J Prosthet Dent 1970;24(4):461-466

14 Phankosol P, Martin JW. Hollow obturator with removable lid. J Prosthet Dent 1985;54(1):98-100 